\title{
HERMITE-HADAMARD TYPE INEQUALITIES FOR MULTIDIMENSIONAL STRONGLY $h$-CONVEX FUNCTIONS
}

\author{
Menguie Feng, Jianmiao Ruan* And Xinsheng Ma
}

Abstract. We establish some Hermite-Hadamard type inequalities for strongly $h$-convex function on balls and ellipsoids, which extend some known results. Some mappings connected with these inequalities and related applications are also obtained.

Mathematics subject classification (2020): 26A51, 26D07, 26D15.

Keywords and phrases: Strongly $h$-convex function, Hermite-Hadamard's inequality, high-dimensional balls, high-dimensional ellipsoids.

\section{REFERENCES}

[1] M. Alomari And M. Darus, The Hadamard's inequality for s-convex function of 2-variables on the co-ordinates, Int. J. Math. Anal., 2 (13) (2008), 629-638.

[2] H. Angulo, J. Gimenez, A. Moros and K. Nikodem, On strongly h-convex functions, Ann. Funct. Anal., 2 (2) (2011), 85-91.

[3] P. Burai And A. HÁZY, On approximately h-convex functions, J. Convex Anal., 18 (2) (2011), 1-9.

[4] W. W. BRECKNER, Stetigkeitsaussagen für eine Klasse verallgemeinerter Konvexer funktionen in topologischen linearen Raumen, Publ. Inst. Math., 23 (1978), 13-20.

[5] S. S. Dragomir, On Hadamard's inequality on a disk, J. Inequal. in Pure Appl. Math., 1 (1) (2000), $11 \mathrm{pp}$ (Article 2).

[6] S. S. Dragomir, On Hadamard's inequality for the convex mappings defined on a ball in the space and applications, Math. Inequal. Appl., 3 (2) (2000), 177-187.

[7] S. S. DRAGOMIR, On the Hadamard's inequality for convex functions on the co-ordinates in a rectangle from the plane, Taiwanese J. Math., 5 (4) (2001), 775-788.

[8] S. S. Dragomir AND S. FitzPatrick, The Hadamard's inequality for s-convex functions in the second sense, Demonstratio Math., 32 (4) (1999), 687-696.

[9] E. K. GodunOVA AND V. I. LEVIN, Neravenstva dlja funkcii sirokogo klassa soderzascego vypuklye monotonnye i nekotorye drugie vidy funkii, Vycislitel, Mat. i. Fiz. Mezvuzov. Sb. Nauc. MGPI Moskva, (1985), 138-142.

[10] A. HÁZY, Bernstein-Doetsch type results for h-convex functions, Math. Inequal. Appl., 14 (3) (2011), 499-508.

[11] M. A. LATIF, On some inequaluties for h-convex functions, Int. J. Math. Anal., 4 (30) (2010), $1473-$ 1482.

[12] M. A. LATIF AND M. Alomafi, On Hadamard-type inequalities for h-convex function on the coordinates, Int. J. Math. Anal., 3 (33) (2009), 1645-1656.

[13] M. MatŁoKA, On Hadamard's inequality for h-convex function on a disk, Appl. Math. Comput., 235 (2014), 118-123.

[14] N. Merentes And K. Nikodem, Remarks on strongly convex functions, Aequationes Math., 80 (2010), 193-199.

[15] C. P. Niculescu AND L.-E. Persson, Convex functions and their applications: A contemporary approach (Second edition), CMS Books in Mathematics, Springer-Verlag, New York, 2018.

[16] K. Nikodem, Strongly convex functions and related classes of functions, in: Th. M. Rassias (Ed.), Handbook of Functional Equations. Functional Inequalities, Springer Optimizations and Its Applications, 95 (2015), 365-405. 
[17] K. Nikodem AND Zs. PÁles, Characterizations of inner product spaces by strongly convex functions, Banach J. Math. Anal., 5 (1) (2011), 83-87.

[18] K. Nikodem, J. L. SÁncheZ And L. SÁnCheZ, Jensen and Hermite-Hadamard inequalities for strongly convex set-valued maps, Math. Aeterna, 4 (2014), 979-987.

[19] A. OLBRYŚ, Representation theorems for h-convexity, J. Math. Anal. Appl., 426 (2015), 986-994.

[20] B. POLYAK, Existence theorems and convergence of minimizing sequences in extremum problems with restictions, Soviet Math. Dokl., 2 (7) (1966), 72-75.

[21] E. S. Polovinkin, Strongly convex analysis, Sbornik Math., 187 (2) (1996), 103-130.

[22] C. E. M. Pearce And A. M. Rubinov, P-functions, quasi-convex functions and Hadamard-type inequalities, J. Math. Anal. Appl., 240 (1999), 92-104.

[23] T. Rajba And S. Wasowicz, Probabilistic characterization of strong convexity, Opuscula Math., 31 (2011), 97-103.

[24] M. Z. Sarikaya, A. Saglam And H. Yildrim, On some Hadamard-Type inequalities for $h$ convex functions, J. Math. Inequal., 2 (3) (2008), 335-341.

[25] R. Schultz, Strong convexity in stochastic programs with complete recourse, J. Comput. Appl. Math., 56 (1994), 3-22.

[26] S. Varošanec, On h-convexity, J. Math. Anal. Appl., 326 (2007), 303-311.

[27] J. P. VIAL, Strong convexity of sets and functions, J. Math. Economy, 9 (1982), 187-205.

[28] J. P. VIAL, Strong and weak convexity of sets and functions, Math. Oper. Res., 8 (2) (1983), 231-259.

[29] X. WANG, J. RUAN AND X. MA, On the Hermite-Hadamard inequalities for $h$-convex functions on balls and ellipsoids, Filomat, 33 (18) (2019), 5817-5886. 